\title{
Período de absorção intestinal de macromoléculas em cabritos recém-nascidos após a ingestão de colostro bovino ${ }^{1}$
}

\author{
Rodrigo Yanaka ${ }^{2}$, Diogo G. de Camargo ${ }^{3}$, Fernanda Bovino ${ }^{3}$, Wildemberto A. \\ Santos $^{4}$, Maíra R. Dócusse ${ }^{4}$, Bruno S. Cavassano ${ }^{4}$ e Francisco L.F. Feitosa ${ }^{5 *}$
}

\begin{abstract}
Yanaka R., Camargo D.G., Bovino F., Santos W.A., Dócusse M.R., Cavassano B.S. \& Feitosa F.L.F. 2012. [Macromolecules intestinal absorption period of goat kids after bovine colostrum intake.] Período de absorção intestinal de macromoléculas em cabritos recém-nascidos após a ingestão de colostro bovino. Pesquisa Veterinária Brasileira 32(8):794802. Curso de Medicina Veterinária da Universidade Estadual Paulista, Campus de Araçatuba, Rua Clóvis Pestana 793, Araçatuba, SP 16050-680, Brazil. E-mail: leydsonf@fmva.unesp.br

After birth goat kids are dependent of colostrum immunoglobulins due to placental characteristics that don't allow macromolecules passage from dam's circulation. According to literature goat kids have colostrum immunoglobulin absorption capability for up to four days. Many physiological aspects of other species have been accepted and used for goats, but those related to passive immunity transference needs more investigation. The goals of the present study was to determine the period of macromolecules passage through gut wall to circulation until 36 hours postpartum and verify the duration of protective humoral immunity transferred by the ingestion of bovine and caprine colostrum. Sixty newborn goat kids were allocated into six treatment groups: $\mathrm{T} 0(\mathrm{n}=25)$, non-restricted natural ingestion of goat colostrum; $\mathrm{T} 1$ $(\mathrm{n}=7)$, bovine colostrum from birth to two hours postpartum; 2 ( $n=7)$, bovine colostrum ingestion between four to six hours after birth; $\mathrm{T} 3(\mathrm{n}=7)$, milk intake until the first eight hours and bovine colostrum administration between 10 to 12 hours postpartum; $T 4(n=7)$, milk ingestion for the first 18 hours and bovine colostrum ingestion between 22 and 24 hours after birth; $\mathrm{T} 5(\mathrm{n}=7)$, milk administration until 30 hours and bovine colostrum intake between 34 to 36 hours postpartum. The total protein (TP), gammaglobulin, immunoglobulin G (IgG) and gamma-glutamyltransferase (GGT) serum concentrations were determined. At birth all neonates presented lower values of the variables, with significant increase of TP and gammaglobulin at two days in groups T $0, \mathrm{~T} 1$ and T 2, IgG and GGT increased in all groups. The treatments T 3, T 4 and T 5 were considered to induce failure of immunity passive transfer. The absorption of macromolecules by kid's intestinal tract occurred until 36 hours postpartum, with better effectiveness until 12 hours. Antibody levels persist up to 75 days after bovine colostrum intake, but at this time their low concentrations doesn't provide adequate protection.

INDEX TERMS: Caprine, gammaglobulin, gamma-glutamyltransferase, immunoglobulin G, passive immunity, total protein.
\end{abstract}

\footnotetext{
${ }^{1}$ Recebido em 18 de julho de 2011.

Aceito para publicação em 4 de abril de 2012.

2 Docente da Unidade Acadêmica de Garanhuns, Universidade Federal de Pernambuco (UFRPE), Av. Bom Pastor s/n, Boa Vista, Garanhuns, PE 55292-270, Brasil.

${ }^{3}$ Doutorando em Ciência Animal, Curso de Medicina Veterinária, Universidade Estadual Paulista (Unesp), Campus de Araçatuba, Rua Clóvis Pestana 793, Araçatuba, SP 16050-680, Brasil.

${ }^{4}$ Discente do Curso de Medicina Veterinária da Unesp, Araçatuba, SP.

${ }^{5}$ Docente do Departamento de Clínica, Cirurgia e Reprodução Animal, Curso de Medicina Veterinária da Unesp, Araçatuba, SP. *Autor para correspondência: leydsonf@fmva.unesp.br
}

RESUMO.- Após o nascimento, os cabritos são dependentes das imunoglobulinas colostrais devido às características placentárias que não permitem a passagem de macromoléculas da circulação materna. De acordo com a literatura, os cabritos possuem capacidade absortiva por até quatro dias. Muitos aspectos fisiológicos de outras espécies são aceitos e utilizados para caprinos, mas aqueles relacionados à transferência de imunidade passiva precisam de investigação. Os objetivos do presente estudo foram determinar o período de passagem de macromoléculas da mucosa intestinal para a circulação e a duração da proteção humoral transferida 
passivamente pela ingestão de colostro bovino e caprino. Sessenta cabritos recém-nascidos foram distribuídos em seis tratamentos: T $0(n=25)$, ingestão natural de colostro caprino à vontade; $\mathrm{T} 1(\mathrm{n}=7)$, colostro bovino entre $\mathrm{o}$ nascimento e duas horas pós-parto; T $2(\mathrm{n}=7)$, ingestão de colostro bovino entre quatro e seis horas pós-nascimento; T $3(n=7)$, leite nas primeiras oito horas e colostro bovino entre 10 e 12 horas pós-parto; T $4(n=7)$, ingestão de leite até 18 horas e colostro bovino entre 22 e 24 horas pós-nascimento; T $5(\mathrm{n}=7)$, leite até 30 horas e ingestão de colostro bovino entre 34 e 36 horas pós-parto. Determinaram-se as concentrações séricas de proteína total (PT), gamaglobulina, imunoglobulina $G$ (IgG) e a atividade sérica de gama glutamiltransferase (GGT). Ao nascimento, todos os neonatos tiveram valores mais baixos das variáveis, com aumento significativo da PT e gamaglobulina, após dois dias, nos grupos T 0, T 1 e T 2; a IgG e GGT aumentaram em todos os grupos. Os tratamentos T 3, T 4 e T 5 foram considerados como indutores de falha de transferência de imunidade passiva. A absorção de macromoléculas pelo trato intestinal dos cabritos ocorreu até 36 horas pós-parto, sendo mais efetiva até 12 horas. Os níveis de anticorpos persistiram até 75 dias após a ingestão de colostro bovino, porém, com concentrações inadequadas.

TERMOS DE INDEXAÇÃO: Caprino, gamaglobulina, gama glutamiltransferase, imunidade passiva, imunoglobulina G, proteína total.

\section{INTRODUÇÃO}

A placenta dos ruminantes é sindesmocorial, ou seja, o epitélio coriônico fica em contato direto com os tecidos uterinos, dificultando a passagem transplacentária das moléculas de imunoglobulinas; portanto, os recém-nascidos dessas espécies são, dessa forma, completamente dependentes dos anticorpos recebidos por meio do colostro (Tizard 2002).

Depois de ser formado em ambiente estéril como o útero, os recém-nascidos encontram-se frente a um meio repleto de agentes causadores de doenças e não são capazes de demonstrar resposta imunológica eficaz no momento do nascimento (Alves 1999).

No manejo do período neonatal, a ingestão do colostro representa uma das mais importantes recomendações dentro do conjunto de medidas sanitárias do rebanho (Simões et al. 2005).

É conhecida, no bezerro holandês, a variação fisiológica das imunoglobulinas séricas relacionada à idade (Ribeiro et al. 1983, Moraes et al. 1997, Fagliari et al. 1998, Feitosa 1998, Costa 2000, Pauletti et al. 2003). De forma geral, segue-se ao pico de concentração sérica, às 24 horas de vida, redução progressiva até os 30 ou 45 dias de idade, após, o que, estabelece-se nova curva ascendente. Esta elevação deve-se à síntese ativa de anticorpos pelo sistema imunológico já competente (Feitosa 1998).

Este fato, dentre outros aspectos fisiológicos, merece ser investigado de forma mais aprofundada nos neonatos da espécie caprina, já que as diferenças entre as espécies devem ser conhecidas e elucidadas. Existe, ainda, dúvida com relação ao período de absorção de imunoglobulinas pelo epitélio intestinal dos caprinos, já que alguns autores acreditam que os animais dessa espécie possuem a capacidade de absorver imunoglobulinas por até quatro dias (Smith \& Sherman 1994, Radostits et al. 2007), ou seja, período esse bem superior ao mencionado para a espécie bovina.

Segundo Perino et al. (1993), a parede intestinal de bovinos neonatos tem a capacidade de absorver macromoléculas intactas nas primeiras 24 horas de vida, e tal característica, provavelmente, também estaria presente nos recém-nascidos da espécie caprina. Desta forma, o mais importante para o animal recém-nascido talvez seja a determinação do tempo limite para que haja o fornecimento do colostro, uma vez que a capacidade do animal em absorver as gamaglobulinas decresce significativamente com o tempo, independente da espécie.

0 uso da atividade enzimática da gama glutamiltransferase (GGT) no soro sanguíneo como meio alternativo para a identificação indireta de bezerros imunologicamente deficientes por inadequada transferência passiva de imunoglobulinas, foi demonstrada por Feitosa et al. (2001). A utilização dessa enzima com essa finalidade foi também observada por Britti et al. (2005) para animais da espécie ovina, onde se denotou correlação significativa entre a concentração de imunoglobulina G (IgG) e a atividade sérica da GGT. Há dúvidas, entretanto, de que estes conceitos possam ser simplesmente extrapolados e/ou completamente aceitos para os animais da espécie caprina.

O nível de gamaglobulinas no soro é significantemente menor em cabritos que recebem $100 \mathrm{~mL}$ de colostro, quando comparados aos que recebem 150 a 200mL em até 90 minutos pós-nascimento (Orsel et al. 2000), demonstrando que, além da qualidade do colostro, a quantidade ingerida está diretamente relacionada à concentração de imunoglobulinas no soro sanguíneo de caprinos.

Existem, na literatura, trabalhos comparando o título de imunoglobulinas em cabritos recém-nascidos alimentados com colostro caprino, bovino, ovino e substitutos comerciais, e todos apontam para resultado comum, qual seja, que nenhum dos substitutos do colostro caprino é adequado como fonte de imunoglobulinas (Goes \& Teixeira 1998, Orsel et al. 2000, Zadoks et al. 2001, Argüello et al. 2004). Porém, no manejo do recém-nascido nos criatórios muitas vezes faz-se necessário o uso de colostros de outras espécies ou fontes para suprir deficiências na sua produção, como no caso de mastite, ou então para evitar a transmissão de determinadas enfermidades, como a artrite encefalite caprina (CAE), que sabidamente possui característica de transmissão vertical através do colostro/leite.

A sobrevivência de cabritos está intimamente vinculada à boa transferência de imunidade passiva por meio do colostro, pois quanto mais elevados os níveis de imunoglobulinas no soro, melhor será, teoricamente, a defesa contra ataques de agentes infecciosos (Santana et al. 2003).

Objetivou-se, portanto, testar a hipótese de que cabritos recém-nascidos possuem adequada capacidade de absorção intestinal de macromoléculas presentes no colostro bovino até 36 horas pós-nascimento, e determinar a duração da proteção humoral transmitida passivamente para os cabritos pelo colostro bovino e caprino. 


\section{MATERIAL E MÉTODOS}

Foram utilizados 60 cabritos, hígidos, nascidos de partos eutócicos, machos e fêmeas, sendo 25 cabritos da raça Bôer, denominados como grupo controle, submetidos ao Tratamento 0 ( $\mathrm{T} 0$ ), após o parto estes animais mamaram colostro à vontade em suas respectivas mães. Outros 35 cabritos, das raças Saanen e Pardo Alpino, foram separados das cabras imediatamente após o nascimento, divididos em cinco grupos com sete animais cada, e submetidos a diferentes manejos de colostro bovino, em uma única mamada, a saber: Tratamento 1 ( $\mathrm{T} 1$ ), fornecimento de colostro até duas horas pós-nascimento; Tratamento 2 (T 2), fornecimento de colostro entre quatro e seis horas pós-nascimento; Tratamento 3 (T 3), administração de leite nas primeiras oito horas de vida, e de colostro entre 10 e 12 horas pós-nascimento; Tratamento 4 (T 4), fornecimento de leite durante as primeiras 18 horas de vida, e de colostro de vaca, entre 22 e 24 horas de nascidos; e Tratamento 5 (T 5), leite administrado até as 30 horas de vida, e colostro, entre 34 e 36 horas.

Os animais tratados com colostro de vaca receberam quantidade correspondente a $10 \%$ do peso vivo, proveniente dos quatro quartos de úbere, de primeira ordenha, obtido de vacas pluríparas, logo após o parto. 0 colostro foi imediatamente avaliado em colostrômetro (Colostrometer ${ }^{\mathrm{TM}}$, Biogenics ${ }^{\odot}, 09359$ Highway, Mapleton, Oregon, EUA), sendo que o "pool" de colostro utilizado apresentava concentração de imunoglobulinas de $90 \mathrm{mg} / \mathrm{mL}$, dentro do intervalo de 51 a $140 \mathrm{mg} / \mathrm{mL}$, pontuação atribuída aos colostros de ótima qualidade, segundo o fabricante. 0 colostro era mantido congelado a $-20^{\circ} \mathrm{C}$ até a sua utilização, sendo descongelado em banho-maria a $35^{\circ} \mathrm{C}$. Após a ingestão de colostro bovino pelos animais dos grupos $\mathrm{T} 1$ a T 5, os mesmos foram alimentados exclusivamente com leite em quantidade equivalente a $10 \%$ do peso vivo/dia, dividida em duas alimentações diárias, não recebendo, assim, qualquer outra possível fonte de imunoglobulina.

Após os cuidados e avaliação física imediata dos recém-nascidos, colheram-se amostras de sangue por venopunção jugular logo após o parto, e antes da ingestão de colostro (zero dia), como também aos dois, sete, 15, 30 e 75 dias de vida. 0 sangue para obtenção do soro era mantido em temperatura ambiente, ao abrigo da luz, até a coagulação e retração do coágulo, e depois centrifugado a 3.000 r.p.m., durante cinco minutos, para melhor separação do soro, sendo divididos em duas alíquotas e transferidos para tubos plásticos, e congelados imediatamente a $-20^{\circ} \mathrm{C}$, até o momento do seu processamento.

Determinou-se a proteína total sérica (PT), utilizando-se refratômetro clínico (Clinical refractometer Master-SUR/NM, Atago, Honcho, Itabashi-ku, Tóquio, Japão). A fração gamaglobulina, pela migração eletroforética para separação das frações proteicas do soro, segundo as técnicas descritas por Friedman (1961) e Kremers et al. (1967), citados por Strufaldi (1987), utilizando fitas de acetato de celulose (Cellogel ${ }^{\circledR}$, MALTA Chemetron, Via Console Flamino 5, Milano, Itália), com leitura e interpretação do fracionamento eletroforético realizadas em densitômetro para eletroforese (Quickscan 2000, Helena Laboratories, Beaumont, Texas, EUA), e por programa computacional (Quickscan 2000 Win, Helena Laboratories, Beaumont, Texas, EUA), com marcação automática das diferentes frações proteicas.

Realizaram-se as determinações séricas da imunoglobulina G segundo a técnica de Fahey \& McKelvey (1965) e Mancini et al. (1965), utilizando-se placas de ágar incorporadas com anticorpos específicos para a classe de imunoglobulina G de bovinos (Bov IgG Test, IDBiotech, Avenue Marie Curie, Issoire, França) e de caprinos (Cap IgG Test, IDBiotech, Avenue Marie Curie, Issoire, França), de acordo com as recomendações do fabricante. A quantidade de imunoglobulina foi estimada observando-se a concentração de imunoglobulina correspondente a cada amostra, pela simulação, no computador, de gráfico com os valores obtidos para os respectivos padrões de IgG, fornecidos com os "kits".

Realizaram-se as análises bioquímicas em analisador bioquímico semi-automatizado (QuickLab 2, Drake Eletrônica Comércio Ltda, São Paulo, Brasil), após verificação do controle de qualidade com controles comerciais $1 \mathrm{H}$ (Qualitrol 1H, Labtest, Lagoa Santa, Minas Gerais, Brasil) e 2H (Qualitrol 2H, Labtest, Lagoa Santa, Minas Gerais, Brasil), além do controle padrão interno do laboratório. Determinou-se a atividade sérica da gama glutamiltransferase de acordo com o método cinético colorimétrico recomendado pela "International Federation of Clinical Chemistry" (IFCC), usando-se "kit" comercial para GGT (GGT, Katal Biotecnológica, cod. 20B, Belo Horizonte, Minas Gerais), segundo técnica modificada de Szasz (1969).

De acordo com os resultados dos testes de normalidade (Kolmogorov-Smirnov) e homocedasticidade (Bartlett), os dados foram submetidos à análise de variância paramétrica (ANOVA) ou não paramétrica (Friedman) com medidas repetidas, seguidos dos testes de Tukey ou Dunn, respectivamente, para verificação das diferenças entre os momentos. Para a determinação das diferenças entre os tratamentos, empregou-se a análise de variância paramétrica (ANOVA) ou não paramétrica (Kruskal-Wallis), seguidos dos testes de Tukey_ou Dunn, respectivamente. Os coeficientes de correlação de Pearson ou de Spearman foram calculados entre as variáveis: proteína total, gamaglobulina, imunoglobulina $\mathrm{G}$ e GGT. Os resultados foram significativos quando $\mathrm{p}<0,05$.

\section{RESULTADOS E DISCUSSÃO}

Quando comparados os teores séricos de proteína total nos diferentes tratamentos de fornecimento de colostro (Quadro 1), observou-se que não houve diferença significativa entre os mesmos, antes da ingestão de colostro, sugerindo não haver diferenças entre as raças ao nascimento e nem influência do manejo adotado para as cabras no período gestacional. Estes valores foram semelhantes aos teores verificados por Santana et al. (2003), de 4,2g/dL em cabritos mestiços das raças Toggemburg, Saanen e Pardo Alpino, e aos constatados por Simões et al. (2005), em cabritos da raça Saanen antes da ingestão de colostro, de 3,75 a 4,00g/ $\mathrm{dL}$, sendo que ambos os autores utilizaram o método do biureto para as determinações.

Os valores séricos de proteína total dos animais de todos os tratamentos no dia 0 (Quadro 1) foram menores que o intervalo de referência para caprinos adultos, de 6,4 a 7,0 g/dL (Kaneko 1989) e de 7,2 $\pm 1,1 \mathrm{~g} / \mathrm{dL}$ (Pérez et al. 2003), devido à menor concentração ou ausência da fração gamaglobulina no soro dos neonatos caprinos (Constant et al. 1994, Simões et al. 2005), visto que estes nascem agamaglobulinêmicos, pelo tipo de placenta, que impede a passagem destas macromoléculas da circulação materna para a fetal (Tizard 2002). Níveis mais baixos de PT antes da ingestão de colostro também foram observados em bezerros (Fagliari et al. 1988, Perino et al. 1993,Feitosa 1998, Jones et al. 2004, Costa et al. 2007, Kindlein et al. 2007).

Aos dois dias de idade, os animais dos tratamentos T 0 a T 2 apresentaram aumento significativo da PT em relação ao do momento zero (Quadro 1); este fato se deveu à ingestão de colostro e consequente aumento dos níveis de gamaglobulinas séricas (Chen et al. 1999, Santana et al. 2003, Simões et al. 2005, Silva et al. 2007). 0 grupo T 0 apresentou 
Quadro 1. Médias e desvios-padrões da proteína total sérica $(\mathrm{g} / \mathrm{dL})$ de cabritos desde o nascimento até 75 dias de vida, submetidos a diferentes manejos no fornecimento de colostro: $\mathbf{T}$ 0, colostro caprino com ingestão voluntária à vontade; $\mathrm{T} 1$, ingestão de colostro bovino até duas horas pós-nascimento; $\mathrm{T} 2$, colostro entre quatro e seis horas pós-nascimento; $\mathrm{T} 3$, leite nas primeiras oito horas de vida e colostro entre 10 e 12 horas pós-nascimento; $T$ 4, leite durante as primeiras 18 horas de vida e colostro de vaca entre 22 e 24 horas de nascidos; e T 5, leite até as 30 horas de vida e colostro entre 34 e 36 horas

\begin{tabular}{ccccccc}
\hline \multirow{2}{*}{ Tratamento } & \multicolumn{7}{c}{ Momento (dias) } \\
\cline { 2 - 7 } & 0 & 2 & 7 & 15 & 30 & 75 \\
\hline \multirow{2}{*}{ T 0 } & $3,76^{\mathrm{Ae}}$ & $6,82^{\mathrm{Aa}}$ & $6,56^{\mathrm{Aab}}$ & $6,05^{\mathrm{Aabc}}$ & $5,63^{\mathrm{Acd}}$ & $5,18^{\mathrm{Bde}}$ \\
& $(0,40)$ & $(0,91)$ & $(0,65)$ & $(0,42)$ & $(0,34)$ & $(0,51)$ \\
T 1 & $4,06^{\mathrm{Ac}}$ & $4,80^{\mathrm{ABab}}$ & $4,37^{\mathrm{Bbc}}$ & $4,20^{\mathrm{Bbc}}$ & $4,30^{\mathrm{Bbc}}$ & $5,08^{\mathrm{Ba}}$ \\
& $(0,22)$ & $(0,54)$ & $(0,58)$ & $(0,57)$ & $(0,57)$ & $(0,34)$ \\
T 2 & $3,54^{\mathrm{Ad}}$ & $4,40^{\mathrm{Bbc}}$ & $4,14^{\mathrm{Bbcd}}$ & $4,31^{\mathrm{Bbcd}}$ & $4,83^{\mathrm{Bab}}$ & $5,51^{\mathrm{Aab}}$ \\
& $(0,49)$ & $(0,52)$ & $(0,22)$ & $(0,47)$ & $(0,53)$ & $(0,63)$ \\
T 3 & $4,17^{\mathrm{Ac}}$ & $4,40^{\mathrm{Bbc}}$ & $4,34^{\mathrm{Bbc}}$ & $4,47^{\mathrm{Bbc}}$ & $5,30^{\mathrm{ABab}}$ & $6,20^{\mathrm{Aa}}$ \\
& $(0,55)$ & $(0,57)$ & $(0,63)$ & $(0,19)$ & $(0,73)$ & $(0,89)$ \\
T 4 & $4,00^{\mathrm{Abc}}$ & $3,69^{\mathrm{Bc}}$ & $3,77^{\mathrm{Bc}}$ & $3,97^{\mathrm{Bbc}}$ & $4,77^{\mathrm{Bab}}$ & $5,46^{\mathrm{Aab}}$ \\
& $(0,64)$ & $(0,47)$ & $(0,56)$ & $(0,69)$ & $(0,70)$ & $(0,40)$ \\
T 5 & $4,00^{\mathrm{Ab}}$ & $3,89^{\mathrm{Bb}}$ & $3,97^{\mathrm{Bb}}$ & $4,20^{\mathrm{Bab}}$ & $4,91^{\mathrm{ABab}}$ & $5,63^{\mathrm{Aab}}$ \\
& $(0,16)$ & $(0,16)$ & $(0,31)$ & $(0,35)$ & $(0,73)$ & $(0,58)$
\end{tabular}

Médias seguidas de letras distintas, maiúsculas na coluna e minúsculas na linha, diferem entre si $(\mathrm{p}<0,05)$.

maior elevação, provavelmente devido à ingestão irrestrita de colostro, enquanto que, nos demais tratamentos, esta se restringia a uma única mamada com volume de $10 \%$ do peso vivo, que possivelmente excedeu a capacidade absortiva de macromoléculas pela mucosa intestinal.

No tratamento T 3 observou-se que não houve diferença significativa da PT entre zero e dois dias (Quadro 1), demonstrando que, às 12 horas de vida, já começa a ocorrer comprometimento da eficácia de absorção de macromoléculas pela mucosa intestinal. Esta analogia encontra supor- te nos resultados dos tratamentos T 4 e T 5, que apresentaram tendência à diminuição da concentração de proteína total aos dois dias de vida, mesmo tendo recebido a mesma proporção de colostro que os demais, contrariando, em parte, as afirmações de Radostits et al. (2007), que descreveram que os animais dessa espécie possuem capacidade de absorver imunoglobulinas por até quatro dias. Apesar de se constatar, mesmo desprovida de significância estatística, absorção de imunoglobulinas em todos os tratamentos (Quadro 2 e 3), a mesma pode não ser suficiente para suprir as necessidades de proteção humoral, principalmente em ambientes com maior desafio antigênico.

Contudo, em todos os grupos que receberam colostro bovino, aos dois dias de idade, os valores de PT foram menores aos obtidos por Santana et al. (2003), de 5,8 a 6,6g/dL, às 24 horas de vida, em cabritos recém-nascidos que ingeriram colostro caprino, e aos obtidos por Simões et al. (2005), que variaram de 5,77 a 7,00g/dL, 30 horas após o fornecimento de colostro de cabras, sob diferentes manejos. Esses resultados declinaram, na maioria dos grupos, até os sete dias de idade. Os teores máximos da proteína total foram observados aos 75 dias de idade para todos os grupos experimentais, estando de acordo com os relatos de Ducker \& Fraser (1976).

Nos dias sete e 15, o tratamento T 0 continuou com níveis de PT mais elevados que os demais grupos (Quadro 1), vindo a apresentar níveis próximos aos obtidos pelos animais que receberam os outros tratamentos, aos 30 e 75 dias de vida.

Quanto à dinâmica das variações da PT, fica evidente a diferença entre os tratamentos, com elevação mais precoce da concentração de PT nos tratamentos que receberam o colostro com intervalo maior após o nascimento.

Não se constatou diferença significativa na concentração sérica de gamaglobulina, antes da ingestão de colostro (momento zero), entre os tratamentos (Quadro 2), apresentando valores abaixo do intervalo de referência, de 900

Quadro 2. Médias e desvios-padrões de gamaglobulina sérica (mg/dL) de cabritos desde o nascimento até $\mathbf{7 5}$ dias de vida, submetidos a diferentes manejos no fornecimento de colostro: $\mathrm{T}$, colostro caprino com ingestão voluntária à vontade; T 1, ingestão de colostro bovino até duas horas pós-nascimento; T 2, colostro entre quatro e seis horas pós-nascimento; $\mathrm{T} 3$, leite nas primeiras oito horas de vida e colostro entre 10 e 12 horas pós-nascimento; T 4, leite durante as primeiras 18 horas de vida e colostro de vaca entre 22 e 24 horas de nascidos; e T 5, leite até as 30 horas de vida e colostro entre 34 e 36 horas

\begin{tabular}{ccccccc}
\hline \multirow{2}{*}{ Tratamento } & \multicolumn{7}{c}{ Momento (dias) } \\
\cline { 2 - 7 } & 0 & 2 & 7 & 15 & 30 & 75 \\
\hline \multirow{2}{*}{ T 0} & $90,40^{\mathrm{Ae}}$ & $3051,60^{\mathrm{Aa}}$ & $2272,00^{\mathrm{Aab}}$ & $1638,40^{\mathrm{Abc}}$ & $1067,20^{\mathrm{Ac}}$ & $1053,60^{\mathrm{Acd}}$ \\
& $(33,72)$ & $(850,37)$ & $(403,15)$ & $(384,01)$ & $(203,19)$ & $(237,59)$ \\
T 1 & $128,57^{\mathrm{Ab}}$ & $1118,57^{\mathrm{ABa}}$ & $948,57^{\mathrm{Aba}}$ & $687,14^{\mathrm{ABab}}$ & $422,86^{\mathrm{Bab}}$ & $582,86^{\mathrm{Bab}}$ \\
& $(54,90)$ & $(412,00)$ & $(404,70)$ & $(374,95)$ & $(171,53)$ & $(136,59)$ \\
T 2 & $77,14^{\mathrm{Ab}}$ & $627,14^{\mathrm{Ba}}$ & $498,57^{\mathrm{Ba}}$ & $365,71^{\mathrm{Bab}}$ & $332,86^{\mathrm{Bab}}$ & $648,57^{\mathrm{Ba}}$ \\
& $(23,60)$ & $(255,45)$ & $(141,71)$ & $(74,80)$ & $(85,97)$ & $(340,02)$ \\
T 3 & $145,71^{\mathrm{Ab}}$ & $511,43^{\mathrm{Bab}}$ & $398,57^{\mathrm{Bab}}$ & $340,00^{\mathrm{Bb}}$ & $575,71^{\mathrm{ABab}}$ & $932,86^{\mathrm{Aab}}$ \\
& $(91,26)$ & $(278,47)$ & $(182,43)$ & $(140,48)$ & $(286,76)$ & $(445,86)$ \\
T 4 & $115,71^{\mathrm{Ac}}$ & $204,29^{\mathrm{Bbc}}$ & $220,00^{\mathrm{Bbc}}$ & $218,57^{\mathrm{Babc}}$ & $322,86^{\mathrm{Bab}}$ & $807,14^{\mathrm{Aab}}$ \\
& $(67,54)$ & $(25,07)$ & $(120,28)$ & $(50,80)$ & $(69,21)$ & $(154,03)$ \\
T 5 & $97,14^{\mathrm{Ac}}$ & $141,43^{\mathrm{Bbc}}$ & $190,00^{\mathrm{Bbc}}$ & $305,71^{\mathrm{Babc}}$ & $527,14^{\mathrm{Bab}}$ & $1151,43^{\mathrm{Aab}}$ \\
& $(28,70)$ & $(39,76)$ & $(100,66)$ & $(144,78)$ & $(247,23)$ & $(674,89)$
\end{tabular}

Médias seguidas de letras distintas, maiúsculas na coluna e minúsculas na linha, diferem entre si $(\mathrm{p}<0,05)$. 
Quadro 3. Médias e desvios-padrões de imunoglobulina G (mg/dL) sérica de cabritos desde o nascimento até 75 dias de vida, submetidos a diferentes manejos no fornecimento de colostro: $T \mathbf{T}$, colostro caprino com ingestão voluntária à vontade; $T$ 1, ingestão de colostro bovino até duas horas pós-nascimento; $T 2$, colostro entre quatro e seis horas pós-nascimento; $\mathrm{T} 3$, leite nas primeiras oito horas de vida e colostro entre 10 e 12 horas pós-nascimento; $T$ 4, leite durante as primeiras 18 horas de vida e colostro de vaca entre 22 e 24 horas de nascidos; e T 5, leite até as 30 horas de vida e colostro entre 34 e 36 horas

\begin{tabular}{ccccccc}
\hline Tratamento & \multicolumn{5}{c}{ Momento (dias) } \\
\cline { 2 - 7 } & 0 & 2 & 7 & 15 & 30 & 75 \\
\hline \multirow{2}{*}{ T 0 } & $3,61^{\mathrm{Af}}$ & $3166,24^{\mathrm{Aa}}$ & $2367,19^{\mathrm{Aab}}$ & $1650,92^{\mathrm{Abcd}}$ & $1318,38^{\mathrm{Acde}}$ & $1711,68^{\mathrm{Abc}}$ \\
& $(655,16)$ & $(1,34)$ & $(1202,14)$ & $(968,63)$ & $(611,02)$ & $(410,20)$ \\
T 1 & $0,00^{\mathrm{Be}}$ & $1485,96^{\mathrm{Aa}}$ & $887,92^{\mathrm{ABb}}$ & $806,62^{\mathrm{ABbc}}$ & $643,20^{\mathrm{ABbc}}$ & $14,94^{\mathrm{Be}}$ \\
& $(11,25)$ & $(0,00)$ & $(610,07)$ & $(436,69)$ & $(327,06)$ & $(304,76)$ \\
T 2 & $0,00^{\mathrm{Bb}}$ & $960,21^{\mathrm{Aa}}$ & $206,22^{\mathrm{BCb}}$ & $118,71^{\mathrm{Bcb}}$ & $30,45^{\mathrm{Bb}}$ & $5,67^{\mathrm{Bb}}$ \\
& $(9,97)$ & $(0,00)$ & $(471,46)$ & $(97,67)$ & $(42,87)$ & $(21,98)$ \\
T 3 & $0,00^{\mathrm{Bb}}$ & $503,95^{\mathrm{Ba}}$ & $123,71^{\mathrm{BCb}}$ & $54,88^{\mathrm{BCb}}$ & $16,44^{\mathrm{Bb}}$ & $6,78^{\mathrm{Bb}}$ \\
& $(7,95)$ & $(0,00)$ & $(303,54)$ & $(61,81)$ & $(33,86)$ & $(3,14)$ \\
T 4 & $0,00^{\mathrm{Be}}$ & $59,98^{\mathrm{Ba}}$ & $42,38^{\mathrm{BCb}}$ & $31,22^{\mathrm{BCbc}}$ & $15,35^{\mathrm{Bd}}$ & $1,58^{\mathrm{Bde}}$ \\
& $(1,01)$ & $(0,00)$ & $(20,49)$ & $(10,29)$ & $(3,90)$ & $(5,11)$ \\
T 5 & $0,00^{\mathrm{Bd}}$ & $55,75^{\mathrm{Ba}}$ & $16,99^{\mathrm{Cb}}$ & $15,96^{\mathrm{Cbc}}$ & $10,43^{\mathrm{Bbcd}}$ & $0,15^{\mathrm{Bd}}$ \\
& $(0,34)$ & $(0,00)$ & $(19,29)$ & $(12,21)$ & $(14,36)$ & $(5,46)$
\end{tabular}

Médias seguidas de letras distintas, maiúsculas na coluna e minúsculas na linha, diferem entre si $(\mathrm{p}<0,05)$.

a $3000 \mathrm{mg} / \mathrm{dL}$ (Kaneko 1989), plenamente justificado pelo estado agama ou hipoglobulinêmico apresentado por ruminantes recém-nascidos (Tizard 2002). Porém, estes foram superiores aos encontrados por Simões et al. (2005), que não detectaram teores desta fração eletroforética, e aos valores descritos por Silva et al. (2007), que variaram de $23 \pm 6$ a $30 \pm 7 \mathrm{mg} / \mathrm{dL}$. Ambos os pesquisadores utilizaram a técnica de eletroforese em gel de agarose no soro de cabritos, antes da ingestão de colostro, sob diferentes manejos de colostro. Essa baixa concentração de gamaglobulinas também foi observada em bezerros (Fagliari et al. 1988, Feitosa 1998, Borges et al. 2001).

Nos tratamentos T 0 a T 2, que receberam colostro mais precocemente, observou-se aumento significativo de gamaglobulinas entre o nascimento e às 48 horas de vida (Quadro 2), em virtude da migração de todas as globulinas, que têm função de anticorpo, para a respectiva fração. Estes achados estão de acordo com Vihan (1988), que encontrou maiores concentrações da respectiva fração até os cinco dias de vida, sugerindo que quanto menor o intervalo até a ingestão de colostro, melhor a taxa de absorção de imunoglobulinas. Seguiu-se, ao valor máximo da concentração sérica, redução contínua da respectiva fração proteica consequente à degradação e à sua combinação com antígenos. A curva obtida para a fração gamaglobulina, coerente com a variação de PT, exibe o formato clássico representativo desse processo fisiológico (Feitosa et al. 2001, Amorim 2002).

As concentrações de gamaglobulinas, para todos os tratamentos que ingeriram colostro bovino, às 48 horas de vida, foram inferiores às dos recém-nascidos que ingeriram colostro caprino sem restrições (Quadro 2), e às descritas por Silva et al. (2007), no mesmo momento de avaliação, em cabritos neonatos que receberam colostro caprino $(2071 \pm 911 \mathrm{mg} / \mathrm{dL})$ e bovino $(2233 \pm 799 \mathrm{mg} / \mathrm{dL})$, na quantidade de 10 a $15 \%$ do peso vivo, em duas ou mais mamadas, ao longo de 48 horas. Os valores foram menores aos dados apresentados por Simões et al. (2005), estudando cabritos da raça Saanen, 30 horas após a ingestão de colostro, com variação de 1,65 a 2,47g/dL. Estas diferenças, em relação ao presente estudo, deveram-se, provavelmente, à limitação da ingestão do colostro bovino em apenas uma mamada, o que, juntamente com os diferentes momentos de fornecimento, influenciou nos níveis de absorção de gamaglobulinas. Já os animais do grupo controle (T 0), apresentaram maiores níveis que os relatados pelos referidos autores, demonstrando que animais que ingerem o colostro naturalmente têm maior teor sérico de gamaglobulinas, e, portanto, melhor proteção imune humoral.

Em semelhança ao observado para os valores de proteína total, os grupos T 3, T 4 e T 5 apresentaram pouca variação na concentração de gamaglobulinas, o que reforça a hipótese de que a absorção de macromoléculas pela mucosa intestinal, 12 horas pós-nascimento, encontra-se suficientemente comprometida, aumentando a possibilidade de ocorrência de falha de transferência passiva nos neonatos após este tempo. No Quadro 2 observou-se que o tratamento T 0 apresentou declínio a partir de dois até 75 dias de vida, enquanto os tratamentos $\mathrm{T} 1$ e $\mathrm{T} 2$ demonstraram declínio até os 30 dias de idade, com posterior aumento. Já os T 3 e T 4 declinaram até os 15 dias, com incremento a partir do primeiro mês de vida, e, o T 5, apresentou ponto inicial de elevação da concentração de gamaglobulinas, aos sete dias de idade. Esta dinâmica apresentada sugere que quanto menor o fornecimento e/ou absorção de globulinas colostrais, mais precocemente se inicia a produção endógena de imunoglobulinas. Com exceção do T 0 , onde se observou tendência de aumento aos 75 dias, devido provavelmente à produção endógena.

As concentrações séricas de imunoglobulina G obtidas por imunodifusão radial em caprinos recém-nascidos antes da primeira mamada de colostro e até os 75 dias de vida estão apresentadas no Quadro 3. A concentração sérica má- 
xima de IgG foi verificada 48 horas após o nascimento, em todos os tratamentos, observando-se diminuição gradativa e contínua até os 75 dias de avaliação (Quadro 3), em virtude do catabolismo das imunoglobulinas provenientes do colostro, como verificado por Silva (2005).

Há trabalhos, em bezerros, demonstrando que altas concentrações de anticorpos séricos podem retardar a produção endógena de imunoglobulinas (Ribeiro et al. 1983, Daniele et al. 1994, Bessi 1996), fato que pode ter contribuído para a dinâmica apresentada pelos animais do tratamento T 0.0 conjunto de informações propõe que a síntese ativa de imunoglobulinas pelo sistema imunológico cada vez mais competente pode ser processo de desenvolvimento mais tardio nos neonatos da espécie caprina.

Segundo Ribeiro et al. (1983) e Machado Neto \& Packer (1986), o momento de concentração mínima da proteína total refletiria a transição entre a fase de catabolismo das imunoglobulinas exógenas e o início da produção endógena da fração imunoglobulina $\mathrm{G}$ e de outras classes de imunoglobulinas. Nos animais dos tratamentos T 1 , T 2 e T 3, os valores mínimos médios nos teores de PT ocorreram por volta dos sete e 15 dias de vida (Quadro 1), enquanto nos cabritos que receberam colostro mais tardiamente, entre 22 e 36 horas de nascidos, as menores concentrações médias foram constatadas aos dois dias de idade, sendo acompanhadas de concomitante elevação dos teores da fração gamaglobulina (Quadro 2). Porém, esta afirmação não pôde ser feita quanto às concentrações de IgG, pois nos tratamentos T 1 a T 5 foi mensurada apenas a IgG bovina, que logicamente não apresentou elevação nos animais da espécie caprina, e sim, decréscimo até os 75 dias de vida, período no qual os menores valores desta imunoglobulina foram observados (Quadro 3).

Além da utilização do proteinograma como forma de se avaliar a efetiva aquisição de imunidade passiva, muitos autores relataram a possibilidade do uso da mensuração da atividade de algumas enzimas, como a aspartatoaminotransferase, gama glutamiltransferase e fosfatase alcalina, geralmente utilizadas na rotina clínica para verificar lesões hepáticas, mas que também estariam presentes no colostro (Rendel et al. 1964, Braun et al. 1982).

A eficácia da utilização da atividade da GGT como método auxiliar para diagnóstico de falha de transferência de imunidade passiva já foi comprovada por outros autores na espécie bovina (Perino et al. 1993, Feitosa et al. 2001), caprina (Silva et al. 2007) e ovina (Maden et al. 2003, Britti et al. 2005).

Como o colostro de vaca, ovelha e cabra contém grande atividade de GGT (Kramer 1989), espera-se que seus valores no soro sejam influenciados pela ingestão de macromoléculas presentes no colostro, ocorrendo a sua passagem através do trato digestório e, posteriormente, à corrente sanguínea do recém-nascido (Fagliari et al. 1996). A análise dos resultados permitiu constatar aumento significativo da atividade da GGT, em todos os grupos, entre zero e dois dias de idade (Quadro 4), em virtude da maior taxa de absorção desta enzima durante o período de maior permeabilidade do epitélio intestinal. De modo geral, todos os grupos, às 48 horas, apresentavam valores superiores ao intervalo de referência relatado na literatura para caprinos adultos, de 20 a 56 UI/L (Kaneko 1989). Após este período, a atividade sérica decresceu gradativamente entre os 15 e 30 dias, comportamento este compatível com os descritos por Braun et al. (1982) e Zanker et al. (2001), quando, então, manteve-se próxima àquela de referência para animais adultos (Kaneko 1989) e de 51,0 $\pm 25,3$ UI/L (Pérez et al. 2003).

Segundo Braun et al. (1982), a atividade sérica de GGT foi baixa ( $\leq 28 \mathrm{UI} / \mathrm{L}$ ) em cabritos recém-nascidos antes de mamar, sendo de $127 \mathrm{UI} / \mathrm{L}$, às 24 horas após o nascimento, seguida de gradativo e contínuo decréscimo durante os

Quadro 4. Médias e desvios-padrões das atividades séricas de gama glutamiltransferase (UI/L) de cabritos desde o nascimento até 75 dias de vida, submetidos a diferentes manejos de fornecimento de colostro: $\mathrm{T} 0$ - colostro caprino com ingestão voluntária à vontade; $\mathrm{T} 1$ - ingestão de colostro bovino

até duas horas pós-nascimento; T 2 - colostro entre quatro e seis horas pós-nascimento; T 3 - leite nas primeiras oito horas de vida e colostro entre 10 e 12 horas pós-nascimento; T 4 - leite durante as primeiras 18 horas de vida e colostro de vaca entre 22 e 24 horas de nascidos; e T 5 - leite até as 30 horas de vida e colostro entre 34 e 36 horas

\begin{tabular}{ccccccc}
\hline Tratamento & \multicolumn{5}{c}{ Momento (dias) } \\
\cline { 2 - 7 } & 0 & 2 & 7 & 15 & 30 & 75 \\
\hline \multirow{2}{*}{ T 0} & $39,70^{\mathrm{Ae}}$ & $187,16^{\mathrm{ABa}}$ & $75,71^{\mathrm{ABb}}$ & $52,85^{\mathrm{Acd}}$ & $46,83^{\mathrm{Ade}}$ & $64,75^{\mathrm{Abc}}$ \\
& $(8,18)$ & $(62,46)$ & $(18,40)$ & $(9,35)$ & $(7,45)$ & $(17,12)$ \\
T 1 & $30,16^{\mathrm{Ac}}$ & $235,42^{\mathrm{Aa}}$ & $96,96^{\mathrm{Aab}}$ & $57,27^{\mathrm{ABabc}}$ & $43,55^{\mathrm{Abc}}$ & $47,88^{\mathrm{Babc}}$ \\
& $(5,04)$ & $(100,74)$ & $(40,16)$ & $(18,53)$ & $(3,41)$ & $(5,06)$ \\
T 2 & $33,33^{\mathrm{Ab}}$ & $134,77^{\mathrm{ABCa}}$ & $59,19^{\mathrm{ABCab}}$ & $43,19^{\mathrm{ABCb}}$ & $46,90^{\mathrm{Aab}}$ & $44,18^{\mathrm{Bab}}$ \\
& $(9,77)$ & $(64,56)$ & $(13,42)$ & $(6,50)$ & $(5,55)$ & $(6,84)$ \\
T 3 & $39,09^{\mathrm{Ab}}$ & $129,93^{\mathrm{ABCa}}$ & $60,72^{\mathrm{ABCab}}$ & $38,46^{\mathrm{BCb}}$ & $40,80^{\mathrm{Ab}}$ & $43,98^{\mathrm{Bab}}$ \\
& $(7,43)$ & $(63,39)$ & $(26,06)$ & $(5,22)$ & $(3,45)$ & $(8,70)$ \\
T 4 & $38,79^{\mathrm{Ab}}$ & $74,86^{\mathrm{Ca}}$ & $50,14^{\mathrm{ABCab}}$ & $44,48^{\mathrm{ABCb}}$ & $47,53^{\mathrm{Aab}}$ & $47,64^{\mathrm{Bab}}$ \\
& $(4,70)$ & $(23,95)$ & $(20,02)$ & $(20,00)$ & $(11,23)$ & $(8,15)$ \\
T 5 & $36,96^{\mathrm{Ab}}$ & $65,67^{\mathrm{Ca}}$ & $38,50^{\mathrm{Cb}}$ & $35,59^{\mathrm{Cb}}$ & $43,34^{\mathrm{Aab}}$ & $46,90^{\mathrm{Bab}}$ \\
& $(10,09)$ & $(15,03)$ & $(7,22)$ & $(4,36)$ & $(6,08)$ & $(5,92)$
\end{tabular}

Médias seguidas de letras distintas, maiúsculas na coluna e minúsculas na linha, diferem entre si $(\mathrm{p}<0,05)$. 
dias subsequentes. Em ovinos, observou-se aumento da atividade sérica de GGT em cerca de 70 vezes, às 24 horas, quando comparados aos valores obtidos logo após o nascimento (Britti et al.,2005).

Aos dois dias de vida, quando comparados os tratamentos T 0 e T1 (Quadro 4), constatou-se nos animais que ingeriram colostro bovino mais precocemente, tendência à maior atividade da GGT, em relação aos animais que ingeriram colostro caprino (Quadro 4), dinâmica semelhante à apresentada por Silva et al. (2007), de 126,6 $\pm 67,1 \mathrm{UI} / \mathrm{L}$, em animais que ingeriram colostro caprino, e de 463,8 $\pm 134,3$ UI/L, nos cabritos que receberam colostro bovino. 0 valor médio deste último foi superior aos dados observados no presente estudo, devido, provavelmente, ao manejo colostral adotado, já que os autores acima descritos os forneciam em duas ou mais mamadas diárias, ao longo de 48 horas, aumentando, com isso, a disponibilidade da referida enzima na mucosa intestinal dos neonatos.

A exemplo do que observou-se nas variáveis do proteinograma, a atividade sérica da GGT dos tratamentos T 4 e $\mathrm{T} 5$, às 48 horas, foi significativamente menor, quando comparada aos animais dos tratamentos T 0 e T 1 (Quadro 4), que receberam colostro mais precocemente, o que enfatiza a suposição de que os animais, após 12 horas de vida, já apresentam comprometimento da capacidade de absorção de macromoléculas pela mucosa intestinal.

Estão descritos no Quadro 5 os coeficientes de correlação entre as diferentes variáveis estudadas. Como esperado, e anteriormente observado, houve correlação significativa entre as variáveis do proteinograma, com dinâmica comportamental semelhante, justificada pela estreita relação fisiológica entre elas, principalmente entre o segundo e 30 - dias de vida.

Na literatura nacional e internacional existem trabalhos que demonstraram correlação positiva entre a atividade da GGT e os valores de imunoglobulina G no soro de ovinos (Maden et al. 2003, Britti et al. 2005), de bovinos (Perino et al. 1993, Fagliari et al. 1996, Feitosa et al. 2001), búfalos (Lombardi et al. 2001) e caprinos (Silva et al. 2007).

Os resultados apresentados diferem dos observados por Silva et al. (2007), em cabritos, que verificaram correlação significativa da GGT apenas com a IgG, às 24 e 48 horas, sendo as correlações com PT e gamaglobulina observadas somente às 72 horas de vida.

A transferência adequada de imunidade passiva não pode ser avaliada unicamente pelo exame físico do animal, devendo, também, serem utilizados exames laboratoriais. Esta avaliação deve ser feita, preferencialmente, entre 24 e 48 horas de vida, que é o período de concentração máxima das imunoglobulinas maternas no soro sanguíneo (Barrington \& Parish 2001). Portanto, os resultados obtidos (Quadro 5) permitem inferir que as determinações séricas de PT por refratometria e da atividade de GGT fornecem subsídios para predizer se houve transferência de imunidade passiva adequada em cabritos recém-nascidos, e que, por serem as metodologias simples e não onerosas, podem ser executadas no campo e/ou em qualquer laboratório de análises clínicas.

A determinação da ocorrência ou não de falha de transferência de imunidade passiva neste período é importante do ponto de vista clínico, já que viabilizaria imediata intervenção veterinária, visando minimizar possíveis riscos de infecções. A utilização do termo "falha de transferência de imunidade passiva" para definir níveis insatisfatórios de proteção imune no animal recém-nascido exige, obrigatoriamente, a definição de parâmetros de normalidade para os teores de alguns componentes séricos circulantes. A avaliação dos animais, quanto ao sucesso ou não na obtenção da imunidade passiva, tem como base a determinação direta ou indireta da concentração das imunoglobulinas circulantes no soro dos recém-nascidos. É sabido da grande variabilidade dos valores de alguns componentes sanguíneos adotados pelos diferentes autores compulsados na literatura internacional, para estabelecer a ocorrência ou não de falha de transferência de imunidade passiva, tais como: Selin et al. (1995) consideraram o nível de 1,5g/dL de gamaglobulinas como sendo satisfatório para fornecer boa imunidade a bezerros; trabalhos de O'Brien \& Sherman (1993) trataram das relações entre baixas concentrações de imunoglobulinas séricas $(<1200,00 \mathrm{mg} / \mathrm{dL})$ e perdas de cabritos por causas infecciosas.

Segundo Nandakumar \& Rajagopalaraja (1983), cabritos que apresentavam valores séricos de imunoglobulinas a partir de $800 \mathrm{mg} / \mathrm{dL}$, possuíam menores taxas de morbidade e mortalidade do que animais com valores menores que $400 \mathrm{mg} / \mathrm{dL}$; resultados semelhantes aos de Mellado et al. (1998), que indicaram concentração mínima de IgG de $800 \mathrm{mg} / \mathrm{dL}$ para melhorar a sobrevivência de cabritos. Mobini et al. (2004) acreditam que níveis inferiores a 0,5g/dL podem significar falha de transferência de imunidade passiva em cordeiros e cabritos. Contrariando as constatações anteriores, Constant et al. (1994) relataram que animais

Quadro 5. Coeficientes de correlação entre as variáveis proteína total (PT), gamaglobulina (Gama), imunoglobulina G (IgG) e gama glutamiltransferase (GGT) de cabritos, desde o nascimento até os 75 dias de vida

\begin{tabular}{lcccccc}
\hline \multirow{2}{*}{ Variáveis } & \multicolumn{7}{c}{ Momento (dias) } \\
\cline { 2 - 7 } & 0 & 2 & 7 & 15 & 30 & 75 \\
\hline PT X GAMA & $0,4515^{* *}$ & $0,9298^{* *}$ & $0,8707^{* *}$ & $0,8263^{* *}$ & $0,6907^{* *}$ & $0,3134^{*}$ \\
PT X IgG & $-0,0689$ & $0,7610^{* *}$ & $0,7493^{* *}$ & $0,7114^{* *}$ & $0,4437^{* *}$ & $-0,2926$ \\
PT X GGT & $0,3187^{*}$ & $0,6412^{* *}$ & $0,5350^{* *}$ & $0,4654^{* *}$ & 0,0041 & $-0,2528$ \\
GAMA X IgG & $-0,0761$ & $0,7828^{* *}$ & $0,8162^{* *}$ & $0,8150^{* *}$ & $0,7117^{* *}$ & $0,3406^{*}$ \\
GAMA X GGT & $-0,1193$ & $0,7185^{* *}$ & $0,5696^{* *}$ & $0,5902^{* *}$ & 0,0226 & $0,2784^{*}$ \\
IgG X GGT & 0,1850 & $0,4965^{* *}$ & $0,4871^{* *}$ & $0,5520^{* *}$ & 0,2359 & $0,6106^{* *}$
\end{tabular}


possuidores de concentrações séricas de imunoglobulinas menores do que $0,4 \mathrm{~g} / \mathrm{dL}$ permaneciam saudáveis, em decorrência das boas condições higiênico-sanitárias a que eram submetidos.

No presente estudo, ao se examinarem os valores individuais dos 35 cabritos que ingeriram colostro bovino, às 48 horas de vida, observou-se que foram registradas variações de 28,26 até $2700,00 \mathrm{mg} / \mathrm{dL}$ de IgG, sendo que, no grupo $\mathrm{T} 1$, cinco animais apresentaram concentração maior que $1000 \mathrm{mg} / \mathrm{dL}$; no grupo T 2, apenas um animal apresentou nível superior a este, e, nos demais grupos experimentais, todos os animais apresentaram menores valores, possuindo, os animais que ingeriram colostro entre 22 e 36 horas de vida ( $\mathrm{T} 4$ e $\mathrm{T}$ 5), níveis próximos aos obtidos antes da ingestão de colostro, o que caracterizaria inadequada transferência de imunidade passiva, mesmo com ingestão controlada, refletida pelo fornecimento de colostro de boa qualidade e em quantidade teoricamente adequada para os cabritos de todos os grupos experimentais.

Sabe-se que a sobrevivência neonatal em ovinos e caprinos parece ser problemática nos países em desenvolvimento, principalmente quando o sistema de manejo não é apropriado às condições locais (Vihan, 1988). Deve-se lembrar que o nível de anticorpos séricos em animais neonatos considerado ideal para a sua proteção contra antígenos é relativo e não absoluto. Inúmeros fatores atuam determinando se um ou vários animais vão ou não sucumbir aos diferentes desafios antigênicos, como o balanço delicado entre a susceptibilidade do hospedeiro ao agente infeccioso e o potencial de infectividade do referido patógeno. Indiscutivelmente, a imunoglobulina G confere proteção aos neonatos frente às agressões bacterianas e virais, mas parece que a susceptibilidade do hospedeiro às doenças infecciosas está mais relacionada com a patogenicidade de alguns microorganismos do que com a sua condição imunológica. Tal fato pôde ser observado no presente trabalho, já que foi constatado apenas um caso de infecção, diagnosticado como pneumonia de origem bacteriana, em um animal do grupo $\mathrm{T} 1$, que recebeu colostro mais precocemente, e que era possuidor de maiores níveis séricos de gamaglobulinas e IgG quando comparados àqueles dos outros grupos que ingeriram colostro bovino, e com níveis séricos de imunoglobulinas considerados como indicadores efetivos de falha de transferência de imunidade passiva. Esta baixa morbidade ocorreu, possivelmente, pelas adequadas condições de manejo adotadas na propriedade a que os animais do presente trabalho pertenciam, já que eram separados ao nascimento e colocados em gaiolas suspensas individuais. É bem provável que as taxas de morbidade e mortalidade fossem elevadas se estes animais tivessem sido alocados em ambientes relativamente contaminados. Aliado às condições de manejo e à rusticidade da espécie, os cabritos, muito provavelmente, necessitam de menores concentrações séricas de imunoglobulinas para a sua proteção que àquelas exigidas para bezerros.

\section{CONCLUSÕES}

Há absorção de macromoléculas presentes no colostro pela mucosa intestinal de cabritos recém-nascidos até as
36 horas de idade; porém, ela se torna extremamente diminuta a partir de 22 horas de vida.

0 período de maior absorção ocorre até seis horas pós-nascimento.

Em cabritos que receberam colostro bovino, uma única vez, as concentrações séricas de IgG são baixas até os 75 dias de vida, não propiciando proteção imune satisfatória.

Nos animais que ingeriram colostro caprino sem restrições, a proteção humoral manteve-se em níveis adequados até os 75 dias de vida.

Agradecimentos.- À Técnica de Laboratório Laine Margareth Gabas pelo auxílio nas análises laboratoriais. À Fundação de Amparo à Pesquisa do Estado de São Paulo (FAPESP) pela concessão de bolsa de mestrado do primeiro autor (Proc.06/58492-2) e auxílio financeiro (Proc.07/55829-9).

\section{REFERÊNCIAS}

Alves F.S.F. 1999. Colostro caprino e sua importância imunológica e nutritiva. Ciênc. Vet. Tróp. 2:131-135.

Amorim R.M. 2002. Valores séricos e hepáticos de elementos minerais, atividade sérica de ceruloplasmina, hemograma, proteinograma e metabolismo oxidativo dos neutrófilos em bezerros da raça Nelore, nascidos de mães com nutrição adequada ou inadequada em cobre e zinco. Tese de Doutorado em Clínica Veterinária, Faculdade de Medicina Veterinária e Zootecnia, Universidade Estadual Paulista, Botucatu. 158p.

Argüello A., Castro N., Zamorano M.J., Castroalonso A. \& Capote J. 2004. Passive transfer of immunity in kid goats fed refrigerated and frozen goat colostrum and commercial sheep colostrum. Small Rumin. Res. 54 (3):237-241.

Barrington G.M. \& Parish S. 2001. Bovine neonatal immunology. Vet. Clin. North Am., Food Anim. Pract. 17(3):463-476.

Besser T.E. \& Gay C.C. 1994. The importance of colostrum to the health of the neonatal calf. Vet. Clin. North Am., Food Anim. Pract. 10(1):107-117.

Bessi R. 1996. Efeito de selênio e vitamina E sobre o desenvolvimento imunológico de bezerros. Dissertação de Mestrado, ESALQ, Piracicaba. 102p.

Borges A.S., Feitosa F.L.F., Benesi F.J., Birgel E.H. \& Mendes L.C.N. 2001. Influência da forma de administração e da quantidade fornecida de colostro sobre a concentração de proteína total e de suas frações eletroforéticas no soro sangüíneo de bezerros da raça Holandesa. Arq. Bras. Med. Vet. Zootec. 53(5):629-634.

Braun J.P., Tainturier D., Laugier C., Bénard P., Thouvenot J.P. \& Rico A.G. 1982. Early variations of blood plasma gamma-glutamyltransferase in newborn calves: A test of colostrum intake. J. Dairy Sci. 65:2178-2181.

Britti D., Massimini G., Peli A., Luciani A. \& Boari A. 2005. Evaluation of serum enzyme activities as predictors of passive transfer status in lambs. J. Am. Vet. Med. Assoc._226(6):951-955.

Castro N., Capote J., Álvarez S. \& Argüello A. 2005. Effects of lyophilized colostrum and different colostrum feeding regimens on passive transfer of immunoglobulin G in Majorera goat kids. J. Dairy Sci. 88:3650-3654.

Chen J.C., Chang C.J., Peh H.C. \& Chen S.Y. 1999. Serum protein levels and neonatal growth rate of Nubian goat kids in Taiwan area. Small Rumin. Res. 32(2):153-160.

Constant S.B., LeBlanc M.M., Klapstein E.F., Beebe D.E., Leneau H.M. \& Nunier C.J. 1994. Serum immunoglobulin G concentration in goat kids fed colostrum or a colostrum substitute. J. Am. Vet. Med. Assoc. 205(12): 1759-1762.

Costa J.N. 2000. Leucograma, metabolismo oxidativo dos neutrófilos, proteinograma e imunoglobulinas de bovinos da raça holandesa (Bos taurus): influência do desenvolvimento etário e da suplementação com vitamina E (acetato de DL-alfa-tocoferol). Tese de Doutorado em Clínica Veterinária, Faculdade de Medicina Veterinária e Zootecnia, Universidade Estadual Paulista, Botucatu. 209p.

Costa J.N., Peixoto A.P.C., Kohayagawa A. \& Souza T.S. 2007. Proteinograma sérico de bezerras da raça holandesa do nascimento aos 150 dias de idade. Rev. Bras. Saúde Prod. Anim. 8(4):267-275. 
Daniele C., Machado Neto R., Baracat R.S., Bessi R. \& Packer I.U. 1994. Efeito de diferentes manejos no fornecimento prolongado de colostro sobre o comportamento imunológico e desempenho de bezerros leiteiros recém-nascidos. Rev. Soc. Bras. Zootec. 23:211-222.

Ducker M.J. \& Fraser J. 1976. A note of the effect of time of uptake of colostrum on blood gamma-globulin levels, mortality and subsequent performance of housed lambs. Anim. Prod. 22:411-414.

Fagliari J.J., Santana A.E., Lucas F.A., Campos Filho E. \& Curi P.R. 1998. Constituintes sanguíneos de bovinos recém-nascidos das raças Nelore (Bos indicus) e Holandesa (Bos taurus) e de bubalinos (Bubalis bubalus) da raça Murrah. Arq. Bras. Med. Vet. Zootec. 50(3):253-262.

Fagliari J.J., Oliveira E.C., Pegorer M.F., Ferrante Junior L.C. \& Campos Filho E. 1996. Relação entre o nível sérico de gamaglobulinas e as atividades de gama glutamiltransferase, fosfatase alcalina e aspartato aminotransferase de bezerros recém-nascidos. Arq. Bras. Med. Vet. Zootec. 48(2):105-112.

Fagliari J.J., Passipieri M., Curi P.R., Ferreira Neto J.M. \& Lucas A. 1988. Valores padrões das proteínas séricas de bovinos da raça Guzerá. II. Proteinograma sérico de bezerros recém-nascidos. Ars Vet. 4:225-232.

Fahey J.L. \& McKelvey E.M. 1965. Quantitative determination of serum immunoglobulins in antibody agar plates. J. Immunol. 94:84.

Feitosa F.L.F. 1998. Dinâmica do proteinograma e da atividade da gama glutamiltransferase no soro sanguíneo de bezerros desde o nascimento até um ano de vida e de vacas antes e após o parto, da raça holandesa. Tese de Doutorado em Clínica Veterinária, Faculdade de Medicina Veterinária e Zootecnia, USP São Paulo. 219p.

Feitosa F.L.F., Birgel E.H., Mirandola R.M.S. \& Perri S.H.V. 2001. Diagnóstico de falha de transferência de imunidade passiva em bezerros através da determinação de proteína total e de suas frações eletroforéticas, imunoglobulinas G e M e da atividade da gama glutamiltransferase no soro sanguíneo. Ciência Rural 31(2):251-255.

Friedman H.S. 1961. A standardized procedure for serum protein electrophoresis on cellulose acetate membrane strips. Clin. Chim. Acta 6(6): 775-781.

Goes C.D.M.M.B. \& Teixeira M.F.S. 1998. Avaliação de cabritos alimentados com diferentes tipos de colostro. Anais 50 Encontro de Pesquisadores da UECE, Fortaleza, p.240.

Jones C.M., James R.E., Quigley J.D. \& McGilliard M.L. 2004. Influence of pooled colostrum or colostrum replacement on IgG and evaluation of animal plasma in milk replacer. J. Dairy Sci. 87:1806-1814.

Kaneko J.J. 1989. Clinical Biochemistry of Domestic Animals. $4^{\text {th }}$ ed. Academic Press, San Diego. 932p.

Kindlein L., Pauletti P., Bagaldo A.R. \& Machado Neto R. 2007. Efeito do fornecimento adicional de colostro sobre as concentrações séricas de IgG, PT e IGF-I de bezerros neonatos. Revta Bras. Saúde Anim. 8(4):375-385.

Kramer J.W. 1989. Clinical enzymology, p.338-363. In: Ibid. (Ed.), Clinical Biochemistry of Domestic Animals. $4^{\text {th }}$ ed. Academic Press, San Diego.

Kremers B., Briere R.O. \& Batasakis J.G. 1967. Reflectance densitometry of cellulose acetate protein electrophoresis. Am. J. Med. Technol. 33:28-34.

Lombardi P. \& Avallone L. 2001. Evaluation of buffalo colostrum quality by estimation of enzyme activity levels. J. Food Prot._64(8):1265-1267.

Machado Neto R. \& Packer I.U. 1986. Flutuação de imunoglobulina sérica em bezerros da raça holandesa submetidos a diferentes regimes de aleitamento. Revta Soc. Bras. Zootec. 15:439-447.

Maden M., Altunok V., Birdane F.M., Aslan V. \& Nizamlioglu M. 2003. Blood and colostrum/milk serum $\gamma$-glutamyltransferase activity as a predictor of passive transfer status in lambs. J. Vet. Med. 50(3):128-131.

Mancini G., Carbonara A.O. \& Heremans J.F. 1965. Immunochemical quantitation of antigens by single radial immunodiffusion. Immunochemistry 2(3):235-254.

Mellado M., Del Angel E., Rebolloso 0. \& García E. 1998. Immunoglobulin $G$ concentration and neonatal survival of goat kids delivered in a pen or on open range. Prev. Vet. Med. 37(1/4):33-39.

Mobini S., Heath A.M. \& Pugh D.G. 2004. Teriogenologia de ovinos e caprinos, p.145-208. In: Pugh D.G. (Ed.), Clínica de Ovinos e Caprinos. Roca, São Paulo.

Moraes M.P., Weiblen R., Silva A.M. \& Tobias F.L. 1997. Evolução da imu- nidade passiva em fêmeas bovinas da raça Holandesa. Ciência Rural 27(3):435-440.

Nandakumar P. \& Rajagopalaraja C.A. 1983. Effect of genetic group, birth weight and type of birth on the post colostral peak of serum immunoglobulin level in kids. Kerala J. Vet. Sci. 14:53-56.

O'brien J.P. \& Sherman D.M. 1993. Serum immunoglobulin concentrations of newborn goat kids and subsequent kid survival through weaning. Small Rumin. Res. 11:71-77.

Orsel K., van Amerongen J.J., Zadoks R.N., van Doorn D.C. \& Wensing T. 2000. Serum gamma globulin titre in goat kids after colostrum administration: Effect of time of administration, and amount and type of colostrum. Tijdschr. Diergeneeskd. 125(23):709-712.

Pauletti P., Machado Neto R., Packer I.U., D’Arce R.D. \& Bessi R. 2003. Quality of colostral passive immunity and pattern of serum protein fluctuation in newborn calves. Sci. Agric. 60(3):453-456.

Pérez J.M., González F.J., Granados J.E., Pérez M.C., Fandos P., Soriguer R.C. \& Serrano E. 2003. Hematologic and biochemical reference intervals for spanish Ibex. J. Wildl. Dis. 39(1):209-215.

Perino L.J., Sutherland R.L. \& Woollen N.E. 1993. Serum gamma-glutamyltransferase activity and protein concentration at birth and after suckling in calves with adequate and inadequate passive transfer immunoglobulin G. Am. J. Vet. Res. 54(1):56-59.

Radostits O.M., Gay C.C., Hinchcliff K.W. \& Constable P.D. 2007. Veterinary medicine: A textbook of the diseases of cattle, horses, sheep, pigs and goats. $10^{\text {th }}$ ed. Elsevier Saunders, Philadelphia. 2156 p.

Rendel J., Aalund O., Freedland R.A. \& Müller F. 1964. The relationship between the alkaline phosphatase polymorphism and blood group 0 in sheep. Genetics 50(5):973-986.

Ribeiro M.F.B., Salcedo J.H.P., Belém P.A.D. \& Faria J.E. 1983. Hipogamaglobulinemia em bezerros. Arq. Bras. Med. Vet. Zootec. 35(4):537-546.

Santana A.F., Silva M.H., Anunciação A.V.M., Guardiani B.P., Ribeiro A.C., Brazil B.N. \& Aguiar C.S. 2003. Transferência de imunidade passiva em cabritos. 5ํㅡㄹ Congresso Pernambucano de Medicina Veterinária, Anais 6oㅡ Seminário Nordestino de Caprino-Ovinocultura, Recife, p.389-390.

Selin S.A., Smith B.P., Cullor J.S., Blanchard P., Farver T.B., Hoffman R., Dilling G., Roden L. \& Wilgenburg B. 1995. Serum immunoglobulins in calves: Their effects and two easy, reliable means of measurement. Vet. Med. 90(4):387-404.

Silva S.L. 2005. Constituintes séricos e hematológicos de cabritos recém-nascidos alimentados com colostro de cabras submetido ou não a tratamento térmico e com colostro de vaca. Dissertação de Mestrado, Faculdade de Ciências Agrárias e Veterinárias, Universidade Estadual Paulista, Jaboticabal. 76p.

Silva S.L., Fagliari J.J., Baroza P.F.J., Cesco F.T.R.S. \& Jorge R.L.N. 2007. Avaliação da imunidade passiva em caprinos recém-nascidos alimentados com colostro de cabras ou colostro de vacas. Ars Vet. 23(2):81-88.

Simões S.V.D., Costa R.G., Souza P.M., Medeiros A.N. \& Vilar A.L.T. 2005. Imunidade passiva, morbidade neonatal e desempenho de cabritos em diferentes manejos de colostro. Pesq. Vet. Bras. 25(4):219-224.

Smith M.C. \& Sherman D.M. 1994. Goat medicine. Williams and Wilkins, Baltimore. 620p.

Strufaldi B. 1987. Prática de Bioquímica Clínica. Faculdade de Ciências Farmacêuticas, São Paulo. 339p.

Szasz G. 1969. A kinetic photometric method for serum gamma-glutamyl transpeptidase. Clin. Chem. 15(2):124-136.

Tizard I.R. 2002. Imunologia Veterinária: uma introdução. 6ª ed. Roca, São Paulo. 532p.

Vihan V.S. 1988. Immunoglobulin levels and their effect on neonatal survival in sheep and goats. Small Rumin. Res. 1:135-144.

Zadoks R.N., Orsel K., Verwer C., de Winter A., van Amerongen J.J. \& Wensing T. 2001. Serum gammaglobulin titre in goat kids after colostrum administration: Effect of commercial colostrum replacers. Tijdschr. Diergeneeskd. 126(20):646-650.

Zanker I.A., Hammon H.M. \& Blum J.W. 2001. Activities of gamma-glutamyltransferase, alkaline phosphatase and aspartate-aminotransferase in colostrum, milk and blood plasma of calves fed first colostrum at 0-2, 6-7, 12-13 and 24-25 h after birth. J. Vet. Med._48(3):179-185. 